\title{
Fracture rates and economic outcomes in patients with osteoporosis prescribed risedronate gastro-resistant versus other oral bisphosphonates: a claims data analysis
}

\author{
Friederike Thomasius ${ }^{1} \cdot$ Santiago Palacios ${ }^{2} \cdot$ Asif Alam $^{3} \cdot$ Mitra Boolell $^{3} \cdot$ Francis Vekeman $^{4} \cdot$ Geneviève Gauthier $^{4}$
}

Received: 5 April 2021 / Accepted: 17 August 2021 / Published online: 6 September 2021

(c) The Author(s) 2021

\begin{abstract}
Summary Patients with osteoporosis prescribed risedronate gastro-resistant had a lower incidence of fractures versus those prescribed other oral bisphosphonates. Administration of risedronate gastric-resistant does not require fasting, and this more convenient dosing administration may explain its improved efficacy.

Purpose Up to half of patients do not follow complex dosing instructions of immediate-release bisphosphonates used for the prevention of osteoporotic fractures, which can result in suboptimal effectiveness. Risedronate gastro-resistant (GR) offers a more convenient dosing option by eliminating the need for fasting. This study compares fracture rates and outcomes between osteoporosis women treated with risedronate GR (GR cohort) versus other oral bisphosphonates (other cohort).

Methods Claims from women with osteoporosis in the USA were analyzed. Patients were classified into the two cohorts based on the first oral bisphosphonate observed (index date) and matched 1:1 based on patient characteristics. Patients were observed for $\geq 2$ years following the index date. Fracture rates, health care resource utilization and costs, and treatment persistence were compared.

Results In total, 2,726 patients were selected in each cohort (median age: 60.0 years). The incidence of fractures was lower in the GR versus the other cohort for any fracture sites (incidence rate ratio, 95\% CI: 0.83, 0.70-0.97) and spine fractures $(0.71,0.54-0.95)$, although the respective rate of medication discontinuation at 2 years was $80.5 \%$ and $74.4 \%$. Time to first fracture was delayed for the GR cohort, reaching statistical significance after 36 months. The GR cohort incurred fewer hospitalizations (incidence rate per 1,000 patient-years: $\mathrm{GR}=106.74$; other $=124.20, p<0.05$ ) translating into lower hospitalization costs per patient per year $(\mathrm{GR}=\$ 3,611$; other $=\$ 4,603, p<0.05)$.

Conclusions Patients prescribed risedronate GR versus other bisphosphonates had a lower incidence of fractures, which may be explained by the fact that the GR formulation is absorbed even when taken with food.
\end{abstract}

Keywords Osteoporosis · Risedronate gastric-resistant · Immediate-release bisphosphonates · Fracture rate ·

Hospitalizations

Mitra Boolell

Mitra.Boolell@theramex.com

1 Frankfurter Hormon Und Osteoporosezentrum, Frankfurt, Germany

2 Palacios' Institute of Women's Health, Madrid, Spain

3 Theramex, London, UK

4 STATLOG, Montreal, Canada

\section{Introduction}

In Europe, in 2010, it was estimated that 22 million women and 5.5 million men aged between 50 and 84 years old were living with osteoporosis [1]. In the USA, approximately 12.3 million individuals older than 50 years were estimated to have osteoporosis in 2020 [2]. These numbers are expected to continue to increase over the next decades with the aging of the population [1]. Men and women with osteoporosis have an increased risk of fractures or bone breaks which can substantially impact their quality of life [3]. Osteoporosis fracture may lead to chronic pain and disability and higher risk of early mortality and pose a substantial financial 
burden on patients, their family, and the health care systems [4-7].

Oral bisphosphonates are the recommended first-line treatment for patients with osteoporosis in the USA and in Europe $[8,9]$. Acting as antiresorptive agents, the use of oral bisphosphonate treatments has been associated with a significant reduction of the risk of fractures in patients with osteoporosis $[7,8,10]$. However, oral bisphosphonates are poorly absorbed, and lack of adherence to complex dosing instructions involving fasting and not lying down after taking the medication can further limit its absorption [11]. Realworld evidence indicates that more than $50 \%$ of patients do not follow all dosing instructions of the immediate-release formulation [12]. A poor absorption of bisphosphonates can result in suboptimal effectiveness and increased risk of fractures [13-15], leading to significant utilization of health care resources and costs $[4,16,17]$.

Risedronate gastro-resistant (GR) was developed with the goal of providing more convenient dosing instructions and reducing the risk of gastrointestinal (GI) side effects by eliminating the need for fasting, without impacting the overall bioavailability and efficacy of the treatment $[11,18]$. The GR formulation has the advantages of a better absorption independent of food intake, which is expected to translate into improved efficacy and a reduction in fracture rates compared to other immediate-release oral bisphosphonates, including alendronate sodium, ibandronate sodium, and risedronate sodium. However, there is limited real-world data comparing fracture rates between patients treated with risedronate GR versus other oral bisphosphonates.

The main objective of the study was to quantify and compare fracture rates among women with osteoporosis treated with risedronate GR versus other oral bisphosphonates. Health care resource utilization (HCRU), health care costs (HCC), and medication persistence and adherence were also compared between the two treatment groups.

\section{Methods}

\section{Data source}

This study used data from the IBM® MarketScan ${ }^{\circledR}$ Commercial and Medicare Supplemental Databases (Q1 2009 to Q4 2019). The MarketScan Commercial and Medicare Supplemental Databases represent health services (both pharmacy and medical) of approximately 130 million employees, dependents, and retirees in the USA with primary or Medicare supplemental coverage through privately insured fee-for-service, point-of-service, or capitated health plans. The databases include de-identified patient-level claims and are compliant with the Health Insurance Portability and Accountability Act (HIPAA).

\section{Study design}

The study used a retrospective observational design. Outcomes were compared between women with osteoporosis treated with risedronate GR (GR cohort) versus other oral bisphosphonates (other bisphosphonates cohort). For each patient, the date of the first observed prescription fill for an oral bisphosphonate was defined as the index date and the treatment initiated on that date as the index treatment. The 6-month period prior to the index date was defined as the baseline period. The observation period of patients spanned the period from the index date to the earliest of the data cutoff date or end of continuous eligibility.

\section{Sample selection and construction of study cohorts}

Adult women with at least one medical claim associated with a diagnosis for osteoporosis (ICD-9 codes, 733.0x; ICD-10 codes, M80.xx, M81.xx) were identified. Patients were included in the study if they had at least one prescription fill for an oral bisphosphonate (alendronate sodium, ibandronate sodium, and risedronate sodium).

Selected women were also required to have continuous eligibility (both pharmacy and medical benefits) for at least 6 months prior to the index date and for at least 2 years following the index date to allow sufficient time to observe fracture events. Furthermore, no treatment switch (i.e., from risedronate GR to other oral bisphosphonates or from other oral bisphosphonates to risedronate GR) were allowed during the minimum 2-year period.

As bisphosphonates can also be used to treat Paget's disease and bone damages from some types of cancer, patients with a diagnosis for Paget's disease or malignant neoplasm recorded during the 6-month baseline period were excluded.

Patients were classified into two mutually exclusive study cohorts based on the treatment initiated on the index date, i.e., risedronate GR cohort and other oral bisphosphonates cohort (including immediate-release risedronate).

\section{Matching}

To balance the patients' profile between cohorts, each woman in the risedronate GR cohort was matched to one woman in the other bisphosphonates cohort with similar demographic and clinical characteristics. Matching factors, evaluated on the index date or at baseline as appropriate, included age, year of the index date, insurance plan type (e.g., comprehensive, preferred provider organization, exclusive provider organization/point-of-service, health maintenance organization), region, Charlson Comorbidity Index [19] categories ( $\leq 2$ and $>2$ ), selected comorbid conditions 
[20] with statistically significant differences between cohorts, presence of a fracture, and the use of selected drugs affecting bone density (abaloparatide, aromatase inhibitors, estrogens, denosumab, gonadotropin-releasing hormone agonists, injectable bisphosphonates, romosozumab, systemic corticosteroids, and teriparatide).

\section{Definition of outcomes and statistical analyses}

Outcomes were compared between the risedronate GR cohort and the other oral bisphosphonates cohort. For fracture rates, a subgroup analysis was performed among patients initiated on alendronate on the index date-the majority of patients in the other oral bisphosphonates cohort.

\section{Fracture rates}

Fracture events were identified based on the presence of medical claims associated with a diagnosis code of fracture during the observation period (see Online Resource 1 for list of diagnosis codes). The incidence of fractures was assessed overall as well as stratified by the main skeletal sites (i.e., hip, pelvis, spine, wrist/arm).

To ensure capturing new fracture as opposed to follow-up care, a definitional algorithm was applied for patients who had more than one medical claim associated with a diagnosis of fracture over the observation period [21, 22]. For two claims indicative of fractures occurring at the same skeletal site, to be considered a new fracture, the date of the second medical claim was required to occur $\geq 90$ days after the first claim. Subsequent medical claims occurring $<90$ days apart were considered follow-up care/fracture aftercare. For two claims indicative of fractures occurring at distinct skeletal sites, to be considered a new fracture, the date of the second medical claim was required to occur $\geq 30$ days after the date of the initial medical claim. Subsequent medical claims occurring $<30$ days apart were considered a single event involving multiple skeletal sites.

For each cohort, the incidence rate (IR) of fractures was calculated as the number of fracture events divided by the total patient-years of observation to account for the different lengths of observation. The IR was compared between cohorts using generalized linear models (GLMs) with a log link and negative binomial distribution, adjusting for matched pairs. Results were reported as incidence rate ratios (IRRs) along with their respective confidence intervals (CIs) and $p$-values.

Time from initiation of the index treatment to the date of the first fracture event was also described using Kaplan-Meier (KM) curves and compared between the two cohorts using the log-rank test.

\section{HCRU and HCC}

All-cause HCRU and HCC during the observation period were assessed and compared between the two cohorts. Health resources components and associated costs evaluated included inpatient stays, emergency department (ED) visits, outpatient visits, and other ambulatory encounters. Total medical costs (i.e., inpatient, ED, outpatient, and other ambulatory encounters costs) as well as all-cause and bisphosphonate-related pharmacy costs were also assessed.

To account for the varying observational time across patients, HCRU were reported as IRs per 1,000 patientyears of observation, and HCC were calculated as weighted average costs and reported per patient per year (PPPY).

HCRU were compared between cohorts using GLMs with a log link and negative binomial distribution, adjusting for matched pairs. Results were reported as IRRs along with their respective CIs and $p$-values.

For HCC, to account for the non-normality of the cost distribution as well as matched pairs, $p$-values and 95\% CIs were estimated using non-parametric bootstrap resampling techniques. Results were reported as incremental HCC with their corresponding $p$-values and CIs. All costs were standardized and reported in 2019 US dollars using the medical care component of the Consumer Price Index [23].

\section{Persistence and adherence to the index medication}

Treatment persistence with the index medication was defined as the time from the date of initiation of the index treatment to the date of discontinuation of the index treatment. Treatment discontinuation was defined as a treatment gap of $\geq 90$ consecutive days - measured between the end of the days of supply of a filled prescription and the date of the subsequent filled prescription for the index treatment, if any. Patients who did not discontinue the index treatment were censored on the date of the first switch to another oral bisphosphonate, the data cut-off date, or the end of insurance eligibility, whichever occurred first. Results were presented graphically using KM curves and compared between the two cohorts using the log-rank test.

Adherence to the index treatment was measured with the medication possession ratio (MPR), calculated as the number of days covered by the treatment over the period of interest divided by the numbers of days during the period. Adherence while on treatment (i.e., from the first to the last dispensing of the index treatment plus the days of supply of the last dispensing) and over fixed periods of 6 months, 1 year, and 2 years was considered. 


\section{Results}

\section{Patient characteristics}

Out of the $1,364,890$ women with $\geq 1$ dispensing for an oral bisphosphonate in the database (risedronate GR, 16,737; other oral bisphosphonates, 1,348,153), 2,726 women prescribed risedronate GR and 2,726 matched women prescribed other oral bisphosphonates were selected after applying the inclusion and exclusion criteria. Among patients in the other bisphosphonates cohort, the majority were initiated on alendronate $(66.3 \%)$ followed by ibandronate $(20.2 \%)$ and risedronate immediate release $(13.5 \%)$. Median age was 60.0 years old in both cohorts, and most patients were from the South region $(45.2 \%)$ or Northeast region $(29.5 \%)$ of the USA (Table 1). Overall, $1.7 \%$ of patients in both cohorts had a diagnosis of fracture recorded during the baseline period. The proportion of patients with a wrist/arm fracture at baseline was slightly higher among GR patients $(0.9 \%$ vs. $0.5 \%, p=0.031$ ).

\section{Fracture rates}

During the observation period, regardless of the site, patients in the GR cohort had a lower incidence of fractures compared to patients in the other bisphosphonates cohort (Table 2). Statistically significant differences were observed for any site of fractures and spine fractures-patients in the GR cohort were associated with a $17 \%$ reduction in overall risk of fracture (IR per 1,000 patient-years: GR, 34.65 vs. other, 42.13; $p<0.05)$ and $29 \%$ reduction in the risk of spine fractures (IR per 1,000 patient-years: GR, 10.84 vs. other, 15.13; $p<0.05)$. A stratification by age group showed that the incidence of fractures, including hip fractures, more than doubled when comparing patients $<65$ to those $\geq 65$ years old as of the index date (Table 3). At each time point considered over the observation period, the rate of incident fractures was lower in the GR cohort compared to the other bisphosphonates cohort, reaching statistical significance at 36 months (GR, 7.08\%; other, 8.67\%; $p=0.037$ ) (Fig. 1).

Results remained consistent and numerically similar when comparing fracture rates between patients treated with risedronate GR versus alendronate (Table 2 ). When compared to patients initiated on alendronate, patients initiated on risedronate GR were associated with a $19 \%$ reduction in the overall risk of fracture (IR per 1,000 patient-years: GR, 33.97 vs. other, 42.53; $p<0.05)$ and $31 \%$ reduction in the risk of spine fracture (IR per 1,000 patient-years: GR, 10.76 vs. other, 15.86 ; $p<0.05)$.

\section{HCRU and HCC}

Compared to patients who were prescribed other bisphosphonates, those who were prescribed risedronate GR had fewer inpatient stays during the observation period (106.74 inpatient stays per 1,000 patient-years for GR vs. 124.20 inpatient stays per 1,000 patient-years for other, $\mathrm{IRR}=0.86$ [0.76-097]). The incidence of ED, outpatient, and other ambulatory encounter visits was not statistically significantly different between the two cohorts (Table 4).

Consistent with their lower utilization of inpatient services, inpatient costs were $\$ 993$ per patient per year lower in the GR cohort compared to the other bisphosphonates cohort $(\mathrm{GR}=\$ 3,611$ vs. other $=\$ 4,603, p<0.05)$. No statistically significant differences were observed for costs associated with ED, outpatient, and other ambulatory encounter visits. When compared to patients in the other bisphosphonates cohort, patients in the GR cohort incurred incremental total pharmacy costs of $\$ 680$ per patient per year-partly driven by higher dispensing costs for oral bisphosphonates (Table 4).

\section{Persistence on the index treatment}

Overall, in both cohorts, most patients discontinued their index treatment within the first 2 years from its initiation. At 2 years after the index date, the rate of discontinuation of the index medication was $80.5 \%$ in the GR cohort and $74.4 \%$ in the other bisphosphonates cohort. The persistence on the index treatment was overall statistically significantly lower for patients in the GR cohort, mainly driven by a higher discontinuation rate within the first few months of treatment initiation (Fig. 2). Average MPR while on treatment at 6 months, 1 year, and 2 years was not statistically significantly different between the two cohorts (Fig. 2).

\section{Discussion}

Results from the current study indicate that over an average observation period of more than 50 months, patients prescribed risedronate GR had lower rates of fracture and in particular a lower rate of spine fractures compared to patients prescribed other bisphosphonates. Of note, although the proportion of patients who had experienced a fracture at any site during the 6-month baseline period was the same in the two treatment cohorts, a slightly higher proportion of patients prescribed risedronate GR experienced a wrist/arm fracture, perhaps indicative of a higher risk of subsequent fractures.

As expected, the incidence of hip fracture, the most expensive fracture type [17], was the lowest among patients under 65 years old and increased sharply in older patients. 
Table 1 Demographic and clinical characteristics

\begin{tabular}{|c|c|c|c|}
\hline & GR patients & Other patients & $p$-value ${ }^{a}$ \\
\hline & $n=2,726$ & $n=2,726$ & \\
\hline \multicolumn{4}{|l|}{ Demographics } \\
\hline Age, mean \pm SD [median] & $62.0 \pm 10.2[60.0]$ & $62.1 \pm 10.3[60.0]$ & 0.815 \\
\hline \multicolumn{4}{|l|}{ Age category, $n(\%)$} \\
\hline $18-49$ yrs & $139(5.1 \%)$ & $139(5.1 \%)$ & - \\
\hline $50-54$ yrs & $440(16.1 \%)$ & $440(16.1 \%)$ & - \\
\hline $55-59$ yrs & $755(27.7 \%)$ & $755(27.7 \%)$ & - \\
\hline $60-64$ yrs & $562(20.6 \%)$ & $562(20.6 \%)$ & - \\
\hline $65-69$ yrs & $241(8.8 \%)$ & $241(8.8 \%)$ & - \\
\hline $70-74$ yrs & $197(7.2 \%)$ & $197(7.2 \%)$ & - \\
\hline $75-79$ yrs & $172(6.3 \%)$ & $172(6.3 \%)$ & - \\
\hline $80+y r s$ & $220(8.1 \%)$ & $220(8.1 \%)$ & - \\
\hline \multicolumn{4}{|l|}{ Census region, $n(\%)$} \\
\hline Northeast & $804(29.5 \%)$ & $804(29.5 \%)$ & - \\
\hline North Central & $379(13.9 \%)$ & $379(13.9 \%)$ & - \\
\hline South & $1,231(45.2 \%)$ & $1,231(45.2 \%)$ & - \\
\hline West & $300(11.0 \%)$ & $300(11.0 \%)$ & - \\
\hline Unknown & $12(0.4 \%)$ & $12(0.4 \%)$ & - \\
\hline \multicolumn{4}{|l|}{ Commercial insurance plan type, $n(\%)$} \\
\hline Basic & $0(0.0 \%)$ & $0(0.0 \%)$ & \\
\hline Comprehensive & $312(11.4 \%)$ & $312(11.4 \%)$ & \\
\hline EPO/POS & $246(9.0 \%)$ & $246(9.0 \%)$ & \\
\hline HMO/POS with capitation & $244(8.9 \%)$ & $244(8.9 \%)$ & \\
\hline PPO & $1,702(62.3 \%)$ & $1,702(62.3 \%)$ & \\
\hline CDHP/HDHP & $183(6.7 \%)$ & $183(6.7 \%)$ & \\
\hline Unknown & $43(1.6 \%)$ & $43(1.6 \%)$ & \\
\hline \multicolumn{4}{|l|}{ Comorbidities during the 6-month baseline period } \\
\hline Patients with $\geq 1$ comorbidity, $n(\%)$ & $1,783(65.4 \%)$ & $1,776(65.2 \%)$ & 0.820 \\
\hline Cardiovascular disease & $424(15.6 \%)$ & $424(15.6 \%)$ & - \\
\hline Celiac disease & $12(0.4 \%)$ & $10(0.4 \%)$ & 0.831 \\
\hline Chronic pulmonary disease & $266(9.8 \%)$ & $261(9.6 \%)$ & 0.853 \\
\hline Depression & $248(9.1 \%)$ & $248(9.1 \%)$ & - \\
\hline Diabetes & $291(10.7 \%)$ & $258(9.5 \%)$ & 0.145 \\
\hline Fatigue & $283(10.4 \%)$ & $252(9.2 \%)$ & 0.166 \\
\hline Gastrointestinal mucositis or urination problem & $330(12.1 \%)$ & $330(12.1 \%)$ & - \\
\hline Hyperparathyroidism & $37(1.4 \%)$ & $34(1.2 \%)$ & 0.807 \\
\hline Hypertension & $857(31.4 \%)$ & $833(30.6 \%)$ & 0.463 \\
\hline Hypertensive chronic kidney disease & $11(0.4 \%)$ & $11(0.4 \%)$ & - \\
\hline Inflammatory bowel disease & $34(1.2 \%)$ & $20(0.7 \%)$ & 0.077 \\
\hline Joint inflammatory disease & $126(4.6 \%)$ & $126(4.6 \%)$ & - \\
\hline Vitamin D deficiency & $262(9.6 \%)$ & $262(9.6 \%)$ & - \\
\hline \multicolumn{4}{|l|}{ Charlson Comorbidity Index } \\
\hline $\mathrm{CCI}$, mean $\pm \mathrm{SD}[$ median] & $0.1 \pm 0.8[0.0]$ & $0.0 \pm 0.8[0.0]$ & $0.028 *$ \\
\hline \multicolumn{4}{|l|}{ CCI category, $\mathrm{n}(\%)$} \\
\hline$\leq 2$ & $2,708(99.3 \%)$ & $2,708(99.3 \%)$ & - \\
\hline \multicolumn{4}{|l|}{ Fractures during the 6-month baseline period } \\
\hline Any site & $47(1.7 \%)$ & $47(1.7 \%)$ & - \\
\hline Hip & $6(0.2 \%)$ & $10(0.4 \%)$ & 0.453 \\
\hline Pelvis & $4(0.1 \%)$ & $2(0.1 \%)$ & 0.683 \\
\hline Spine & $13(0.5 \%)$ & $23(0.8 \%)$ & 0.089 \\
\hline
\end{tabular}


Table 1 (continued)

\begin{tabular}{|c|c|c|c|}
\hline & GR patients & Other patients & $p$-value ${ }^{\mathrm{a}}$ \\
\hline Wrist/arm & $25(0.9 \%)$ & $13(0.5 \%)$ & $0.031 *$ \\
\hline $\begin{array}{l}\text { Dispensing of } \geq 1 \text { drug affecting bone density during the 6-month base- } \\
\text { line period }{ }^{b}, n(\%)\end{array}$ & $1,001(36.7 \%)$ & $1,001(36.7 \%)$ & - \\
\hline Duration of observation period (months), mean \pm SD [median] & $52.0 \pm 21.7[46.8]$ & $56.4 \pm 22.6[52.4]$ & $<.001 *$ \\
\hline
\end{tabular}

Notes:

$S D$ standard deviation

${ }^{a} p$-values were calculated using paired $t$-tests for continuous variables, and McNemar tests for categorical variables

${ }^{\mathrm{b}}$ Drugs included abaloparatide, aromatase inhibitors, estrogens, denosumab, gonadotropin-releasing hormone agonists, injectable bisphosphonates, romosozumab, systemic corticosteroids, and teriparatide

*Significant at the 5\% level

Table 2 Fracture rates

GR vs. other patients

GR patients
$n=2,726$

Other patients

\begin{tabular}{|c|c|c|c|c|c|c|c|}
\hline & \multicolumn{3}{|l|}{$n=2,726$} & \multicolumn{3}{|l|}{$n=2,726$} & \multirow{2}{*}{$\begin{array}{l}\text { IRR } \\
(95 \% \mathrm{CI})^{\mathbf{a}, \mathbf{b}} \\
\text { Unadjusted }\end{array}$} \\
\hline & $\begin{array}{l}\text { Total number of } \\
\text { fractures }\end{array}$ & $\begin{array}{l}\text { Total patient- } \\
\text { years of observa- } \\
\text { tion }\end{array}$ & $\begin{array}{l}\text { IR of fractures, } \\
\text { per } 1,000 \text { patient- } \\
\text { years }\end{array}$ & $\begin{array}{l}\text { Total number } \\
\text { of fractures }\end{array}$ & $\begin{array}{l}\text { Total patient- } \\
\text { years of obser- } \\
\text { vation }\end{array}$ & $\begin{array}{l}\text { IR of } \\
\text { fractures, } \\
\text { per } 1,000 \\
\text { patient-years }\end{array}$ & \\
\hline Any site & 409 & 11,804 & 34.65 & 540 & 12,818 & 42.13 & $0.83(0.70-0.97)^{*}$ \\
\hline Hip & 100 & 11,804 & 8.47 & 114 & 12,818 & 8.89 & $0.98(0.69-1.40)$ \\
\hline Pelvis & 28 & 11,804 & 2.37 & 43 & 12,818 & 3.35 & $0.71(0.41-1.23)$ \\
\hline Spine & 128 & 11,804 & 10.84 & 194 & 12,818 & 15.13 & $0.71(0.54-0.95)^{*}$ \\
\hline Wrist/arm & 180 & 11,804 & 15.25 & 215 & 12,818 & 16.77 & $0.91(0.73-1.13)$ \\
\hline
\end{tabular}

GR vs. alendronate patients

GR patients

$n=1,807$

Total number of fractures

\begin{tabular}{|c|c|c|c|c|c|c|c|}
\hline & GR patients & & & Alendronate p & tients & & \\
\hline & $n=1,807$ & & & $n=1,807$ & & & IRR \\
\hline & $\begin{array}{l}\text { Total number of } \\
\text { fractures }\end{array}$ & $\begin{array}{l}\text { Total patient- } \\
\text { years of obser- } \\
\text { vation }\end{array}$ & $\begin{array}{l}\text { IR of fractures, } \\
\text { per } 1,000 \\
\text { patient-years }\end{array}$ & $\begin{array}{c}\text { Total number } \\
\text { of fractures }\end{array}$ & $\begin{array}{l}\text { Total patient- } \\
\text { years of } \\
\text { observation }\end{array}$ & $\begin{array}{l}\text { IR of } \\
\text { fractures, } \\
\text { per } 1,000 \\
\text { patient- } \\
\text { years }\end{array}$ & $\begin{array}{l}(95 \% \text { CI })^{\mathbf{a}, \mathbf{b}} \\
\text { Unadjusted }\end{array}$ \\
\hline Any site & 262 & 7,712 & 33.97 & 354 & 8,323 & 42.53 & $0.81(0.66-0.98)^{*}$ \\
\hline Hip & 71 & 7,712 & 9.21 & 80 & 8,323 & 9.61 & $0.99(0.65-1.51)$ \\
\hline Pelvis & 16 & 7,712 & 2.07 & 26 & 8,323 & 3.12 & $0.68(0.35-1.33)$ \\
\hline Spine & 83 & 7,712 & 10.76 & 132 & 8,323 & 15.86 & $0.69(0.49-0.97)^{*}$ \\
\hline Wrist/arm & 112 & 7,712 & 14.52 & 132 & 8,323 & 15.86 & $0.91(0.70-1.20)$ \\
\hline
\end{tabular}

Notes:

$C I$ confidence interval, $I R$ incidence rate, $I R R$ incidence rate ratio

${ }^{a}$ Incidence rate ratios were estimated with generalized linear models with log link and negative binomial distribution with robust error variances to account for the matched pairs. Incidence rate ratios may differ from the ratio of the incidence rates because of adjustments for overdispersion

${ }^{\mathrm{b}}$ An IRR $<1$ indicates a lower incidence of fracture per patient-year among women treated with risedronate GR

*Significant at the $5 \%$ level

Overall, the incidence of fractures more than doubled in patients $\geq 65$ versus $<65$ years old. In general, the lower rates of fractures observed in the present study compared to previously published results from observational studies are consistent with the relatively young age of the studied population [24-26]. 
Table 3 Fracture rates by age group

Patients $<65$ years

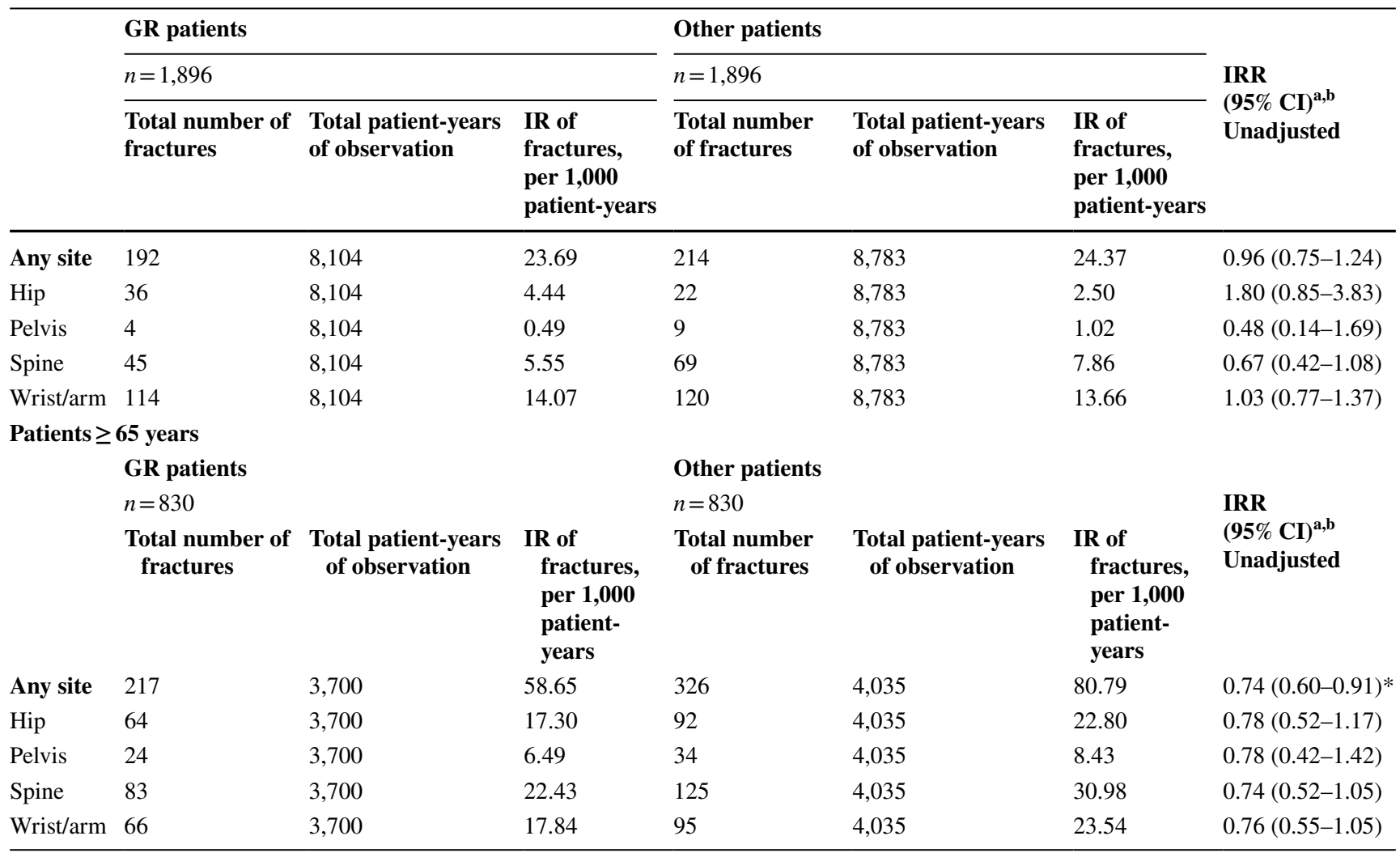

Notes:

$C I$ confidence interval, $I R$ incidence rate, $I R R$ incidence rate ratio

${ }^{a}$ Incidence rate ratios were estimated with generalized linear models with log link and negative binomial distribution with robust error variances to account for the matched pairs. Incidence rate ratios may differ from the ratio of the incidence rates because of adjustments for overdispersion

${ }^{\mathrm{b}} \mathrm{An}$ IRR $<1$ indicates a lower incidence of fracture per patient-year among women treated with risedronate GR

*Significant at the $5 \%$ level

Indeed, in a study using claims data from commercially insured patients (all patients $<65$ years old; mean age: 56.0 years old), the authors estimated incidence rates of fractures at any site between 15.4 and 16.1 per 1,000 patient-years for bisphosphonates [25]. In a similar study using claims from Medicare insured patients (all patients $\geq 65$ years old; mean age, 78.2 years old), the authors estimated at 56.3 per 1,000 patient-years the incidence rate of fractures at any site [24].

Compared to patients prescribed other bisphosphonates, those who were prescribed risedronate GR were associated with a higher rate of treatment discontinuation, especially during the first few months after the index date. A potential explanation for this observation could be the 4 to 6 times higher out-of-pocket costs observed for risedronate GR than that for other bisphosphonates (mean [median] out-ofpocket costs per dispensing, 28-30-day supply, GR, \$42.39 [\$37.95] vs. other, \$10.72 [\$6.10]; 84-90-day supply, GR,
$\$ 83.69$ [\$69.71] vs. other, \$21.13 [\$11.88]). This observation is further supported by a well-documented body of literature on the detrimental impact of increased out-of-pocket costs on medication compliance and persistence, in particular for chronic conditions [27-32].

This study offers a unique perspective on the fracture rates of patients prescribed risedronate GR versus other oral bisphosphonates in real-world settings. Several randomized clinical trials have assessed the efficacy of bisphosphonates, and the body of evidence from these studies suggests no differential effect on fracture rates between bisphosphonates [33]. However, in real-world settings, patients' behavior towards their medication may impact the ability of bisphosphonates to prevent fractures.

Lack of persistence and poor compliance are known challenges with bisphosphonates, all of which may impact the overall efficacy of bisphosphonates [14, 33-35]. A systematic literature review of 89 prospective and retrospective 


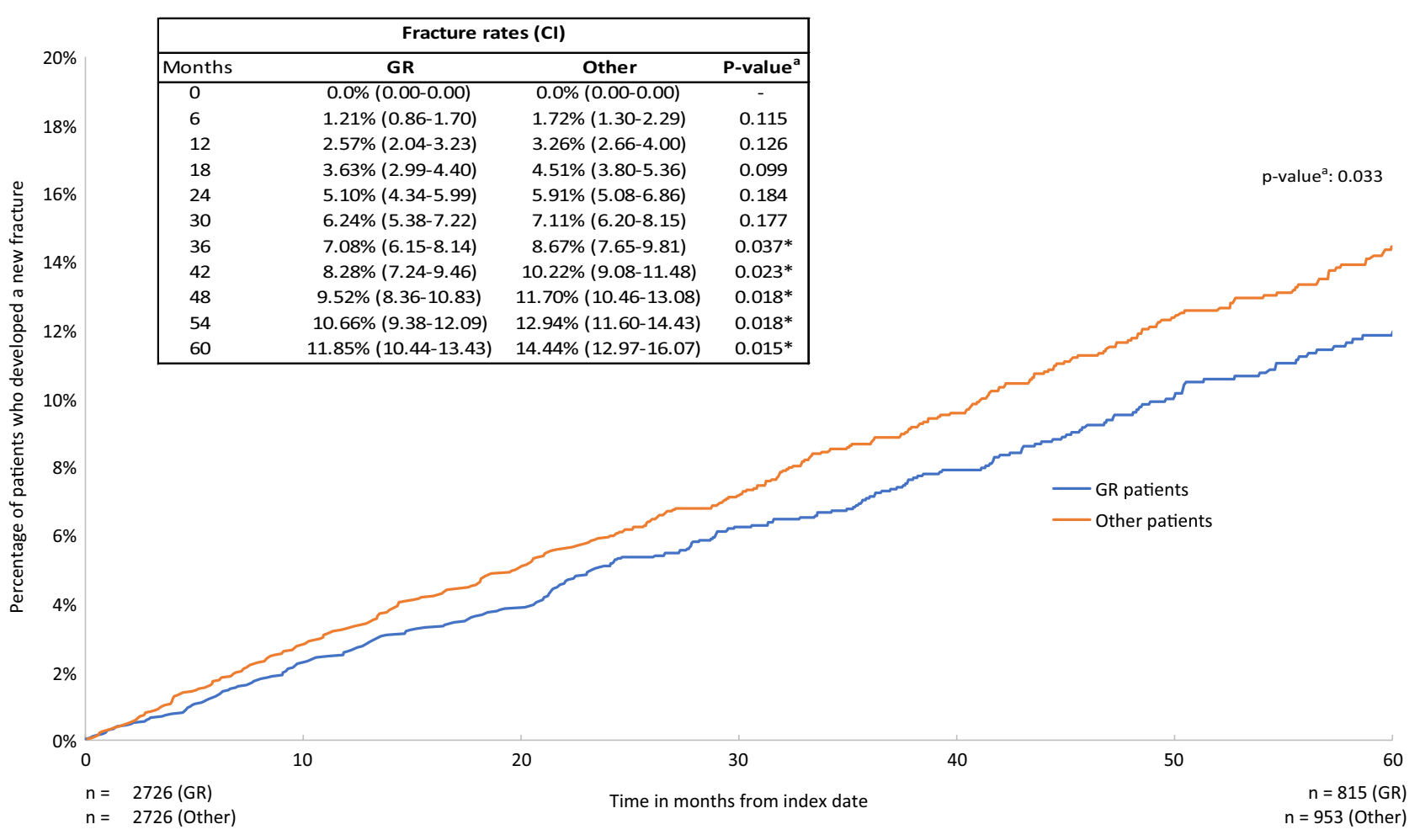

Note:

a. P-values are based on the log-rank test

*Significant at the $5 \%$ level

Fig. 1 Development of first fracture (any site)

observational studies examining patient adherence and persistence to oral bisphosphonates in adults with osteoporosis found that mean persistence rates ranged from 17.7 to $74.8 \%$ at 1 year and from 12.9 to $60.6 \%$ at 2 years. Similarly, compliance rates ranged from 31.7 to $72.0 \%$ at 1 year and from 34.5 to $47.9 \%$ at 2 years across studies [33]. Although reasons for the lack of persistence and compliance are likely multifactorial, complex dosing instructions as well as GI side effects have been reported as potential reasons [15, 33-35].

Adding to the detrimental impact on bisphosphonates effectiveness of poor medication persistence and compliance is the poor compliance with dosing instructions. Absorption of oral bisphosphonate by the system is poor-usually less than $1 \%$ on average - and may be further limited by concurrent intake of food and beverage [11]. As such, to derive the full benefits of immediate-release formulations of oral bisphosphonates, patients are required to follow a strict dosing schedule - the drug is typically required to be taken on an empty stomach $\geq 30$ to 60 min before the first food, drink, or other medications of the day. Furthermore, patients must not lie down for 30 min after taking the medication [36-38].

Real-world evidence indicates that a significant fraction of patients do not follow the complex dosing instructions of the immediate-release formulation of bisphosphonates [12]. In a survey of 363 women with osteoporosis aged $\geq 55$ years old, $40.5 \%$ reported not being compliant with dosing instructions ensuring adequate absorption, $34.7 \%$ were not compliant with dosing instructions preventing adverse events, and as many as $56.5 \%$ were not compliant with all dosing instructions [12]. Other external factors, such as the calcium content in tap water, may also interfere with the absorption of bisphosphonates [39].

The lower rates of fractures observed among patients in the risedronate GR cohort, despite their lower persistence on the medication, could be explained by its more convenient dosing administration. Indeed, among patients remaining on bisphosphonates, those on risedronate GR are more likely to receive an improved medication benefit because of its absorption irrespective of fasting compared to the complex and, hence often not followed, dosing administration of immediate-release bisphosphonates.

Likely reflecting their lower incidence of fractures, patients prescribed risedronate GR were associated with a lower utilization of inpatient services, which translated into lower inpatient costs. The amount of health care resources and the associated costs diverted by osteoporotic fractures are substantial [4, 16, 17, 40]. For instance, using claims 
Table 4 Health care resource utilization and costs

\begin{tabular}{|c|c|c|c|c|}
\hline \multirow[t]{2}{*}{ HCRU, per 1,000 patient-years } & GR patients & Other patients & \multicolumn{2}{|c|}{$\operatorname{IRR}(95 \% \mathrm{CI})^{\mathrm{a}}$} \\
\hline & $n=2,726$ & $n=2,726$ & & \\
\hline Inpatient visits & 106.74 & 124.20 & \multicolumn{2}{|c|}{$0.86(0.76-0.97)^{*}$} \\
\hline ED visits & 533.29 & 549.38 & \multicolumn{2}{|c|}{$0.97(0.88-1.07)$} \\
\hline Outpatient visits & $16,384.69$ & $15,681.44$ & \multicolumn{2}{|c|}{$1.04(0.99-1.08)$} \\
\hline Other ambulatory encounter ${ }^{\mathrm{b}}$ & $2,775.82$ & $2,726.07$ & \multicolumn{2}{|c|}{$1.04(0.95-1.13)$} \\
\hline \multirow[t]{2}{*}{$\mathrm{HCC} \mathrm{PPPY}{ }^{\mathrm{c}}$, mean $_{ \pm} \mathrm{SD}$} & GR patients & Other patients & \multirow{2}{*}{\multicolumn{2}{|c|}{ Cost difference $[95 \% \mathrm{CI}]$}} \\
\hline & $n=2,726$ & $n=2,726$ & & \\
\hline Inpatient & $3,611 \pm 11,367$ & $4,603 \pm 16,230$ & -993 & $(-1,805 ;-285)^{*}$ \\
\hline Emergency department & $890 \pm 2,762$ & $900 \pm 2,360$ & -10 & $(-156 ; 128)$ \\
\hline Outpatient & $7,305 \pm 13,691$ & $6,768 \pm 12,471$ & 538 & $(-195 ; 1,311)$ \\
\hline Other ambulatory encounter ${ }^{\mathrm{b}}$ & $694 \pm 3,396$ & $792 \pm 3,720$ & -97 & $(-293 ; 102)$ \\
\hline Total medical costs & $12,500 \pm 23,005$ & $13,063 \pm 25,778$ & -562 & $(-1,995 ; 819)$ \\
\hline Pharmacy & $4,335 \pm 12,980$ & $3,655 \pm 9,192$ & 680 & $(64 ; 1,485)^{*}$ \\
\hline Oral bisphosphonates & $387 \pm 523$ & $149 \pm 297$ & 238 & $(214 ; 262)^{*}$ \\
\hline
\end{tabular}

Notes:

Costs are reported in 2019 US dollars

$C I$ confidence interval, $E D$ emergency department, $H C C$ health care costs, $H C R U$ health care resource utilization, IRR incidence rate ratio, $P P P Y$ per patient per year

${ }^{a}$ Incidence rate ratios were estimated with generalized linear models with log link and negative binomial distribution with robust error variances to account for the matched pairs

${ }^{b}$ Other ambulatory encounters include mainly patient home, independent laboratory, skilled nursing facilities, and other unlisted facilities

${ }^{\mathrm{c}}$ Costs PPPY are weighed by the number of days in the patients' observation period

*Significant at the $5 \%$ level

data from the USA, Tran et al. found that the all-cause incremental yearly health care costs of commercially insured women with versus without incident osteoporotic fracture over a period of 5 years following the fracture were $\$ 77,370$, $\$ 28,737, \$ 23,155, \$ 21,478$, and $\$ 18,835$, respectively [40]. Even a small decrease in the risk of fracture has thus the potential for significant health care resources and health care costs saving on the long term.

Results from this study should be interpreted in light of some limitations. First, given the retrospective nature of the data used, this study did not attempt to establish causal inference. Instead, findings should be interpreted as association-level results. Second, because the databases used include patients with a commercial health plan or a Medicare Supplemental health plan, the study sample may not be representative of the general osteoporosis population. This is underscored by the relatively young age of studied patients. Third, the higher out-ofpocket cost associated with risedronate GR compared to that of other bisphosphonates may be the source of a selection bias. Another potential source of confounding comes from the fact that the database used does not include the necessary clinical information to identify patients at a higher risk of fracture. Fourth, osteoporosis and other conditions considered in this study were identified based on diagnostic codes recorded on administrative claims used for billing purposes, which in some instance could reflect suspected rather than confirmed clinical diagnoses. It is also possible that not all diagnoses are systematically recorded on claims; thus, underreporting of certain conditions is also a possibility. Similarly, the incidence of spine fracture may be underestimated as most cases do not come to medical attention. Fifth, claims data only provide information on filled prescriptions, not on how medications are actually consumed. Finally, the HCC reported are likely to be an underestimation of the total costs resulting from fractures as they do not capture administrative costs of third-party payers for claims processing, out-of-pocket costs, indirect costs (e.g., productivity loss), or other intangible costs.

Despite their lower persistence, patients prescribed risedronate GR were associated with a lower incidence of fractures compared to those prescribed other oral bisphosphonates, leading to lower utilization of inpatient services which translated into lower inpatient costs. These results are consistent with the hypothesis that the more convenient dosing administration of risedronate GR could improve the absorption of bisphosphonate and help patients with osteoporosis get an improved benefit of treatment. 


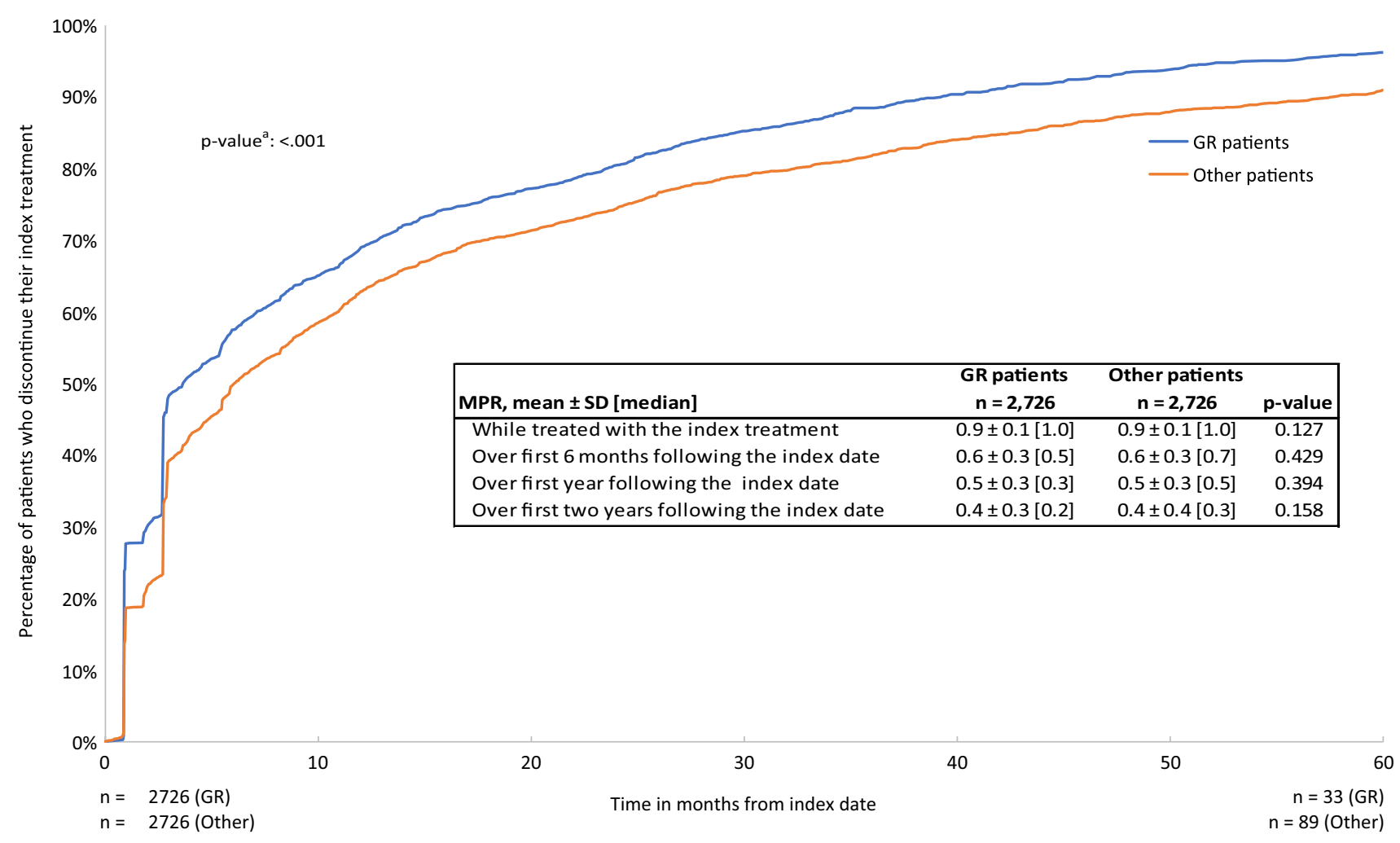

Notes:

a. P-value based on the log-rank test.

Fig. 2 Persistence and adherence to the index medication

Supplementary Information The online version contains supplementary material available at https://doi.org/10.1007/s00198-021-06108-w.

Acknowledgements Writing/editorial assistance in the preparation of this article was provided by Marie-Noëlle Robitaille from STATLOG Inc. and was funded by Theramex.

Author contribution FT, SP, AA, MB, FV, and GG contributed to the conception, design, and interpretation of the data. FV and GG performed the analyses. All authors provided constructive feedback during manuscript development and have read and approved the final manuscript.

Funding This study was funded by Theramex, which owns the marketing rights of Actonel ${ }^{\circledR}$ (risedronate) gastro-resistant in Europe (excluding the UK and Ireland).

Data Availability The data that support the findings of this study are available from IBM ${ }^{\circledR}$ Watson Health ${ }^{\mathrm{TM}}$, but restrictions apply to the availability of these data, which were used under a license agreement for the current study and, accordingly, are not publicly available. Access to the IBM® MarketScan ${ }^{\circledR}$ Commercial Database and the Multi-State Medicaid Database can be requested by contacting IBM® Watson Health ${ }^{\mathrm{TM}}$.

Code availability Codes can be provided upon request.

\section{Declarations}

Ethics approval Not applicable. Data are de-identified and comply with the Health Insurance Portability and Accountability Act (HIPAA) of 1996. Accordingly, this study did not require approval from an institutional review board or collection of inform consent.

Consent to participate Not applicable.

Consent for publication Not applicable.

Conflicts of interest FT has received fees for lectures and consultancy or investigator fees from Amgen, Gedeon Richter, Lilly, Hexal, Kyowa Kirin, Hologic, Novartis, Stada, Synexus, Theramex, and UCB. SP is a consultant for Pfizer, Amgen, MSD, Procare, Health, Bayer, Besins, Sérélys Shinogi, Exeltis, Gedeon Richter, Theramex, and UCB. AA and MB are employees of Theramex. FV and GG are employees of STATLOG, Inc., which has received research funding from Theramex for this study.

Open Access This article is licensed under a Creative Commons Attribution-NonCommercial 4.0 International License, which permits any non-commercial use, sharing, adaptation, distribution and reproduction in any medium or format, as long as you give appropriate credit to the original author(s) and the source, provide a link to the Creative Commons licence, and indicate if changes were made. The images or other third party material in this article are included in the article's Creative 
Commons licence, unless indicated otherwise in a credit line to the material. If material is not included in the article's Creative Commons licence and your intended use is not permitted by statutory regulation or exceeds the permitted use, you will need to obtain permission directly from the copyright holder. To view a copy of this licence, visit http://creativecommons.org/licenses/by-nc/4.0/.

\section{References}

1. Hernlund E, Svedbom A, Ivergård M et al (2013) Osteoporosis in the European Union: medical management, epidemiology and economic burden: a report prepared in collaboration with the International Osteoporosis Foundation (IOF) and the European Federation of Pharmaceutical Industry Associations (EFPIA). Arch Osteoporos 8:136. https://doi.org/10.1007/s11657-013-0136-1

2. Wright NC, Looker AC, Saag KG et al (2014) The recent prevalence of osteoporosis and low bone mass in the United States based on bone mineral density at the femoral neck or lumbar spine. J Bone Miner Res 29:2520-2526. https://doi.org/10.1002/ jbmr.2269

3. Brenneman S, Barrett-Connor E, Sajjan S et al (2006) Impact of recent fracture on health-related quality of life in postmenopausal women. J Bone Min Res 21:809-816

4. Weycker D, Li X, Barron R et al (2016) Hospitalizations for osteoporosis-related fractures: economic costs and clinical outcomes. Bone Reports 5:186-191. https://doi.org/10.1016/j.bonr.2016.07. 005

5. Svedbom A, Hernlund E, Ivergård M et al (2013) Osteoporosis in the European Union: a compendium of country-specific reports. Arch Osteoporos 8:137-218. https://doi.org/10.1007/ s11657-013-0137-0

6. Abrahamsen B, van Staa T, Ariely R et al (2009) Excess mortality following hip fracture: a systematic epidemiological review. Osteoporos Int 20:1633-1650

7. Haentjens P (2010) Meta-analysis: excess mortality after hip fracture among older women and men. Ann Intern Med 152:380. https://doi.org/10.7326/0003-4819-152-6-201003160-00008

8. Kanis JA, Cooper C, Rizzoli R, Reginster J-Y (2020) Correction to: European guidance for the diagnosis and management of osteoporosis in postmenopausal women. Osteoporos Int 31:209-209. https://doi.org/10.1007/s00198-019-05184-3

9. Adler RA, El-Hajj Fuleihan G, Bauer DC et al (2016) Managing osteoporosis in patients on long-term bisphosphonate treatment: report of a Task Force of the American Society for Bone and Mineral Research. J Bone Miner Res 31:16-35. https://doi.org/ 10.1002/jbmr.2708

10. Jeremiah MP, Unwin BK, Greenawald MH, Casiano VE (2015) Diagnosis and management of osteoporosis. Am Fam Physician 92:261-268. https://doi.org/10.1093/innovait/ins123

11. Pazianas M, Abrahamsen B, Ferrari S, Russell RGG (2013) Eliminating the need for fasting with oral administration of bisphosphonates. Ther Clin Risk Manag 9:395-402. https://doi.org/10.2147/ TCRM.S52291

12. Vytrisalova M, Touskova T, Ladova K et al (2015) Adherence to oral bisphosphonates: 30 more minutes in dosing instructions matter. Climacteric 18:608-616. https://doi.org/10.3109/13697 137.2014.995164

13. Hiligsmann M, Reginster J-Y (2019) Cost-effectiveness of gastroresistant risedronate tablets for the treatment of postmenopausal women with osteoporosis in France. Osteoporos Int 30:649-658

14. Adachi J, Lynch N, Middelhoven H et al (2007) The association between compliance and persistence with bisphosphonate therapy and fracture risk: a review. BMC Musculoskelet Disord 8:97. https://doi.org/10.1186/1471-2474-8-97

15. Siris ES, Fan CPS, Yang X et al (2016) Association between gastrointestinal events and compliance with osteoporosis therapy. Bone Reports 4:5-10. https://doi.org/10.1016/j.bonr.2015.10.006

16. Cutler RL, Fernandez-Llimos F, Frommer M, et al (2018) Economic impact of medication non-adherence by disease groups: a systematic review. BMJ Open 8

17. Budhia S, Mikyas Y, Tang M, Badamgarav E (2012) Osteoporotic fractures. Pharmacoeconomics 30:147-170. https://doi.org/10. 2165/11596880-000000000-00000

18. McClung MR, Balske A, Burgio DE et al (2013) Treatment of postmenopausal osteoporosis with delayed-release risedronate 35 mg weekly for 2 years. Osteoporos Int 24:301-310. https://doi.org/ 10.1007/s00198-012-2175-7

19. Quan H, Sundararajan V, Halfon $P$ et al (2005) Coding algorithms for defining comorbidities in ICD-9-CM and ICD-10 administrative data. Med Care 43:1130-1139. https://doi.org/10.1097/01. mlr.0000182534.19832.83

20. Siris ES, Fan C-PS, Yang X et al (2015) Association between gastrointestinal events and compliance with osteoporosis therapy. Bone Reports 30:5-10

21. Bynum JPW, Bell JE, Cantu RV et al (2016) Second fractures among older adults in the year following hip, shoulder, or wrist fracture. Osteoporos Int 27:2207-2215. https://doi.org/10.1007/ s00198-016-3542-6

22. Balasubramanian A, Zhang J, Chen L et al (2019) Risk of subsequent fracture after prior fracture among older women. Osteoporos Int 30:79-92. https://doi.org/10.1007/s00198-018-4732-1

23. Consumer Price Index (CPI) Databases : U.S. Bureau of Labor Statistics. https://www.bls.gov/cpi/data.htm. Accessed 3 Mar 2021

24. Yusuf AA, Cummings SR, Watts NB et al (2018) Real-world effectiveness of osteoporosis therapies for fracture reduction in post-menopausal women. Arch Osteoporos 13:33. https://doi.org/ 10.1007/s11657-018-0439-3

25. Reynolds AW, Liu G, Kocis PT et al (2018) Comparison of osteoporosis pharmacotherapy fracture rates: Analysis of a marketScan ${ }^{\circledR}$ claims database cohort. Int J Endocrinol Metab 16:e12104. https://doi.org/10.5812/ijem.12104

26. Gallagher AM, Rietbrock S, Olson M, Van Staa TP (2008) Fracture outcomes related to persistence and compliance with oral bisphosphonates. J Bone Miner Res 23:1569-1575. https://doi. org/10.1359/jbmr.080510

27. Seaman K, Sanfilippo F, Bulsara M et al (2020) Predictors of ceasing or reducing statin medication following a large increase in the consumer copayment for medications a retrospective observational study. Public Heal Res Pract 30:29121905. https://doi.org/ 10.17061/phrp29121905

28. Baker-Goering MM, Roy K, Howard DH (2019) Relationship between adherence to antihypertensive medication regimen and out-of-pocket costs among people aged 35 to 64 with employersponsored health insurance. Prev Chronic Dis 16:E32. https://doi. org/10.5888/pcd16.180381

29. Pawaskar MD, Xu L, Tang Y et al (2018) Effect of medication copayment on adherence and discontinuation in Medicare beneficiaries with type 2 diabetes: a retrospective administrative claims database analysis. Diabetes Ther 9:1979-1993. https://doi.org/10. 1007/s13300-018-0489-y

30. Heidari P, Cross W, Crawford K (2018) Do out-of-pocket costs affect medication adherence in adults with rheumatoid arthritis? A systematic review Semin Arthritis Rheum 48:12-21

31. Després F, Forget A, Kettani FZ, Blais L (2016) Impact of patient reimbursement timing and patient out of pocket expenses on medication adherence in patients covered by private drug insurance 
plans. J Manag Care Spec Pharm 22:539-547. https://doi.org/10. 18553/jmcp.2016.22.5.539

32. Doshi JA, Zhu J, Lee BY et al (2009) Impact of a prescription copayment increase on lipid-lowering medication adherence in veterans. Circulation 119:390-397. https://doi.org/10.1161/ CIRCULATIONAHA.108.783944

33. Fatoye F, Smith P, Gebrye T, Yeowell G (2019) Real-world persistence and adherence with oral bisphosphonates for osteoporosis: a systematic review. BMJ Open 9

34. Diez-Perez A, Naylor KE, Abrahamsen B et al (2017) International Osteoporosis Foundation and European Calcified Tissue Society Working Group. Recommendations for the screening of adherence to oral bisphosphonates. Osteoporos Int 28:767-774. https://doi.org/10.1007/s00198-017-3906-6

35. Cramer JA, Amonkar MM, Hebborn A, Altman R (2005) Compliance and persistence with bisphosphonate dosing regimens among women with postmenopausal osteoporosis. Curr Med Res Opin 21:1453-1460

36. FDA Ibandronate sodium: highlights of prescribing information. https://www.accessdata.fda.gov/drugsatfda_docs/label/2015/ 021455s019lbl.pdf. Accessed 28 Feb 2021

37. FDA Risedronate sodium: highlights of prescribing information. https://www.accessdata.fda.gov/drugsatfda_docs/label/2009/ 020835s035lbl.pdf. Accessed 28 Feb 2021
38. FDA Alendronate sodium: highlights of prescribing information. https://www.accessdata.fda.gov/drugsatfda_docs/label/2012/ 021575s017lbl.pdf. Accessed 28 Feb 2021

39. Morr S, Cuartas E, Alwattar B, Lane JM (2006) How much calcium is in your drinking water? A survey of calcium concentrations in bottled and tap water and their significance for medical treatment and drug administration. HSS J 2:130-135

40. Tran O Uncovering the total costs of osteoporosis-related fractures in US postmenopausal women. In: Present. Am. Soc. Bone Miner. Res. Annu. Meet. Sept. 11-15, 2020 (virtual Meet. https:// www.healio.com/news/endocrinology/20200915/prolonged-effec ts-from-osteoporotic-fractures-drive-health-care-indirect-costs. Accessed 28 Feb 2021

Publisher's note Springer Nature remains neutral with regard to jurisdictional claims in published maps and institutional affiliations. 